\title{
高温金属表面に衝突する単一水滴の変形挙動*
}

\author{
森山昭**.荒木和 男 $^{* *}$

\section{Deforming Behaviors of a Water Droplet Impinging onto Hot Metal Surfaces}

Akira Moriyama and Kazuo Araki

\begin{abstract}
Synopsis :
Deformations of a water droplet impinged on the hot metal surfaces were studied. Thin film flow at the bottom part of the deformed droplet was regarded as a potential flow and theoretical velocity components and pressure distributions in it were given. The droplet is decelerated by the pressure difference at the bottom and the upper surfaces.

From mass and energy balances of the thin film flow theoretical relations of the film thickness and the radial extent of the thin film flow were derived and compared with the experimental data which had been obtained from measurements on the photographs presented by WACHTERS et al. ${ }^{11}$

For an initial impacting velocity of $v_{0}=63 \mathrm{~cm} / \mathrm{s}$, the theory on the film thickness and the radial extent well coincided with the experimental data both in the cases taking no account of the surface tension of the droplet and taking account of it. When $v_{0}$ is $139 \mathrm{~cm} / \mathrm{s}$, the radial extents theoretically predicted with taking account of the surface tension only at the spherical portion of the droplet coincide with the data. In the similar calculations under conditions of $v_{0}=220 \mathrm{~cm} / \mathrm{s}$ it was found that the coincidences were within about $25 \%$.
\end{abstract}

\section{1. 緒言}

高温金属のスプレー冷却操作では，金属表面に衝突す る各水滴の変形挙動が重要な役割を演じている．膜沸騰 領域における微小な水滴の衝突変形過程について WACHTERS ら'が示した写真をみると，衝突滴は底部で高温 表面に沿つて放射状の薄膜流を生じて変形する。したが つて，この薄膜流と高温表面の間に生成する過熱蒸気膜 を介して高温金属から水滴への熱移動が進行すると考え られ，滴底の薄膜流の大きさが伝熱速度に重要な関連を もつと思われる。

滴底の過熱蒸気膜内の伝熱機構は，いわ叫，ラィデ ンフロスト現象における場合と本質的な差はないと考え られるが，この問題について，著者の一人は，すでに， 報告した2)3).

一方, 衝突滴の変形挙動に関する理論は, まだ, 知ら れていない，滴の変形過程は，滴内流動に局所的な表面 張力の变化の効果が加わり, かなり複雑な問題になつて いるが，本報では，滴底に擬定常的なポテンシャル流を
想定して, 変形する滴の底部の薄膜流の厚さ, および, 半径について比較的簡単な理淪式を導く.この理論は, WACHTERS ら1)の写真の結果をかなりよく説明できる.

\section{2. 理}

\section{論}

考察にあたり，つぎの仮定を設ける。古なわち，（i） 高温金属表面に衝突した水滴は底部で Fig. 1 のように 変形するが，滴の球形残部 ( $\mathrm{ABB}^{\prime} \mathrm{A}$ 部) は衝突前の形状 を保持する.（ii）球形残部内の各点の相対的な流動はな い.（iii）滴底の薄膜流の厚さ $d *$ は一様であるとする. (iv) 滴底部における薄膜流の粘性を無視する.（v)重力 効紧は無視できる.（vi) 蒸発による滴の質量減少は 0.1 \%以下と推算2されれるで無視できる.

仮定 (i ) は写真1) から近似的に満足されている。この ため，仮定 (ii )が成立する. 写真 ${ }^{1)}$ は変形中の滴のプロ フィルを示すので, 周緑の影像にさえぎられて $d *$ を直 接知ることができないが，周縁部の厚みが比較的小さい ので，仅定(iii)は妥当であると思われる. 仮定(iv)は， 滴底が過熱蒸気膜に支えられ，外部からの則断㐫力が小

* 昭和 52 年 6 月 6 日受付 (Received June 6, 1977)

** 名古屋工業大学材料開発研究施設 工博 (Meterial Research Laboratory, Nagoya Institute of Technology, Gokisho-machi Shōwa-ku Nagoya 466) 


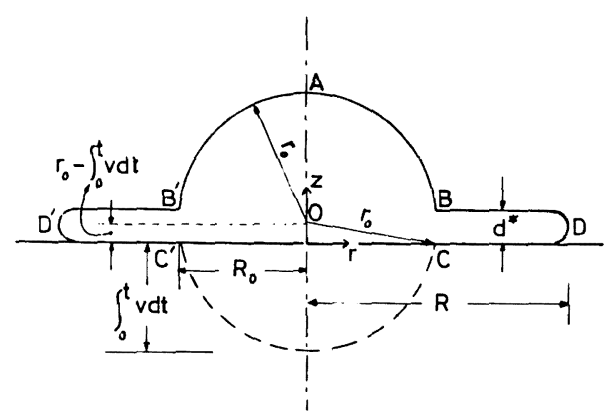

Fig. 1. Schematic profile of impinging droplet onto hot metal surface.

さいこと，また，仮定 $(\mathrm{v})$ は直径 $0.2 \mathrm{~cm}$ ていど以下の 小水滴を取扱うことに基ゔいている.

\section{$2 \cdot 1$ 変形に伴う滴底部の流れ}

滴底には薄膜流が存在する. 薄膜流の $\mathrm{BCC}^{\prime} \mathrm{B}^{\prime}$ 領域 内の流れについて, 擬定常条件下のポテンシャル流の運 動方程式 (1)および ( 2)を考える.

$$
\begin{aligned}
& \rho\left(v_{r} \frac{\partial v_{r}}{\partial r}+v_{z} \frac{\partial v_{r}}{\partial z}\right)=-\frac{\partial P}{\partial r} \\
& \rho\left(v_{r} \frac{\partial v_{z}}{\partial r}+v_{z} \frac{\partial v_{z}}{\partial z}\right)=-\frac{\partial P}{\partial z}
\end{aligned}
$$

滴底および中心軸上には境界条件 (3)および ( 4 )式が, また, $\mathrm{BB}^{\prime}$ 面のレベルで滴の衝突運動に起因する一様法 線方向流速成分, $-v, \mathrm{BC}$ 面では一様接線方向流速成 分， $v_{R_{0}}$ が存在すると考光る.

$$
\begin{aligned}
& z=0,0 \leqq r<R_{0} \text { で } v_{z}=0 \\
& r=0,0 \leqq z \leqq d^{*} \text { で } v_{r}=0 \ldots . . \\
& z=d^{*}, 0 \leqq r<R_{0} \text { で } v_{z}=-v \\
& r=R_{0}, 0 \leqq z \leqq d^{*} \text { で } v_{r}=v_{R_{0}}
\end{aligned}
$$

流れ関数 $\varphi$ を(7) および (8) 式で定義すると，(1)〜 (6)式の解として $(9) 〜(12)$ 式を得る(付録 A).

$$
\begin{aligned}
& v_{r}=(1 / r) \partial \varphi / \partial z \\
& v_{z}=-(1 / r) \partial \varphi / \partial r \\
& v_{r}=v_{R_{0}} r / R_{0} \\
& v_{z}=-2 v_{R_{0}} z / R_{0} \\
& \varphi=c_{1}+v r^{2} z / 2 d * \\
& P=P_{t}-(\rho / 2)\left(v_{R_{0}} r / R_{0}\right)^{2}-(\rho / 2)\left(v z / d^{*}\right)^{2}
\end{aligned}
$$

$c_{1}$ および $P_{t}$ は積分定数である.

$2 \cdot 1 \cdot 1 d *$ と $R_{0}$ の関係

条件式 (15) と解 (10) 式より(13) 式の関係を得る.

$$
d^{*}=R_{0} v / 2 v_{R_{0}}
$$

(13)式は $\mathrm{BCC}^{\prime} \mathrm{B}^{\prime}$ 部に関する物質収支関係にほかなら ない. 後述するように $R_{0}$ はvの関数であるので, $v$ と $v_{R_{0}}$ の関係がわかれば，(13)式からd*がvの関数とし
て求められる.

\section{$2 \cdot 1 \cdot 2$ 衝突滴にはたらく力}

仮定 ( i )および ( ii)に基づき, 滴底の圧力と, それに 対応与る滴の上表面の压力の差は，(12)式で $z=0$ とお いて得る $P$ および $z=d *$ と括いて得るそれの差にひ としい，そこで，滴底の蒸気膜が衝突滴に及ぼす力， $F$ が(14)式で表わせる.

$$
F=\pi R_{0}^{2} \rho v^{2} / 2
$$

\section{$2 \cdot 1 \cdot 3$ 流れの全生 $P_{t}$}

滴の変形挙動における表面張力効果はウェーバー数, $\mathrm{We}=2 \rho r_{0} v_{0}^{2} / \sigma$ に依存すると思われる. WACHTERSら ${ }^{1)}$ よれば，滴が高温金属面に衝突してのち，金属面から離 脱する際に, $W e<80$ の条件では, 滴が単一滴の状態を 保持するが, We $>80$ の条件では, 数個以上の微細滴に 分裂して飛散する.しかし, 衝突中の滴の变形挙動にお ける We 数の寄与については, この種の知見はない.

いま, 滴の表面張力を無視すると, 滴の $\mathrm{BB}^{\prime}$ 面の中心 付近の静压は大気圧にひとしいと考えることができるの で(15)式が成立する.

$$
r=0, z=d * \tau ゙ P=0 .
$$

(15)式を(12)式に代入して，

$$
P_{t}=\rho v^{2} / 2
$$

$P_{t}$ が流れの全圧であることは容易に確かめられる.

さて, 滴のB点 (Fig. 1) 付近では, 滴表面の曲率半 径が連続的に変化して凹部を形成している. 正確な表面 形状を知ることなしには，B点付近の流れの静压を指定 することが困難であるが，ここでは，仮定(V)に基づき (12)式に(17)式の条件を適用して，(13)式における $v_{R_{0}}$ こvの関係として簡単な(18)式を導くことができる.

$$
\begin{aligned}
& r=R_{0}, \quad z=0 \text { で } P=0 \\
& v_{R_{0}}=v \cdots \cdots \ldots \ldots \ldots \ldots
\end{aligned}
$$

この場合， $P_{t}$ として(16)式が使われている.

一方，(15)式の条件の代りに球形表面 $\mathrm{BAB}^{\prime}$ の曲率に 起因する表面張力压 $2 \sigma / r_{0}$ を考虑すると, 境界条件(19) 式が成立する.

$$
r=0, \quad z=d * \tau ゙ \quad P=2 \sigma / r_{0}
$$

（19）式を（12）式に代入すると，(16) 式に代る全圧の式 (20) ガ得られる.

$$
P_{t}=2 \sigma / r_{0}+\rho v^{2} / 2
$$

滴底の薄膜流の先端 $\mathrm{D}$ 付近にも表面張力圧が存在する が，このものは，近似的に $2 \sigma / d^{*}$ で表わすことができ る.この結果, $\mathrm{BB}^{\prime}$ 面および点 $\mathrm{D}$ を含む薄膜流先端面を 端面とする流管に擬定常条件下の BERNOULLI の定理を 適用すると $(21)$ 式となる.

$$
2 \sigma / r_{0}+\rho_{v}^{2} / 2=2 \sigma / d *+\rho v_{R}^{2} / 2
$$


この場合は，(13)式にかえて，物質収支式(22)を使用寸 るのが得策である.

$$
R_{0}^{2} v=2 R d * v_{R}
$$

\section{$2 \cdot 2$ 薄膜流の厚さ $\boldsymbol{d}^{*}$ および半径 $\boldsymbol{R}$}

$2 \cdot 2 \cdot 1$ 表面張力を考虑しない場合

(13)および(18)式から厚さ $d *$ は簡単な $(23)$ 式で与 えられる.

$$
d^{*}=R_{0} / 2
$$

(23) 式右辺の $R_{0}$ は, 幾何学的に(24)式によつて $v$ に関 係づけられる (Fig. 1 参照).

$$
R_{0}^{2}=\left(2 r_{0}-\int_{0}^{t} v d t\right) \int_{0}^{t} v d t
$$

この結果，(23)および(24)式から $d^{*}$ がvの関数となり もし, vを衝突開始後の経過時間 $t$ の関数として与える ことができれば， $d^{*}$ の時間的変化が計算できる. 必要 となる $v$ と $t$ と関係は次節で導く.

薄膜流の半径 $R$ は, 仮定 (vi)に基づき(25)式で与える ことができる.

$$
R^{2}=R_{0}^{2}+\left\{2 r_{0}^{3} \mp\left(2 r_{0}^{2}+R_{0}^{2}\right) \sqrt{r_{0}^{2}-R_{0}^{2}}\right\} / 3 d^{*}
$$

ただし，(-): $r_{0} \geqq \int_{0}^{t} v d t, \quad(+): r_{0}<\int_{0}^{t} v d t$

に対応する・(24)および(25)式の関倸は表面張力を考虑 する場合でも，そのままなりたつ。

$2 \cdot 2 \cdot 2$ 表面張力を考慮する場合

(21)および $(22)$ 式から $v_{R}$ を消去して整理すると, $v$ の関数として $d^{*}$ が(27)式で与えられる.

$$
\begin{gathered}
d^{*}=\left(\frac{2 \sigma}{\rho U}-\frac{N}{2 R_{0}^{2}}\right)+\frac{1}{2 R_{0}^{2} U} \\
\sqrt{\left(\frac{4 \sigma R_{0}^{2}}{\rho}-N U\right)^{2}+R_{0}^{2} U\left(\frac{16 \sigma N}{\rho}+R_{0}^{4} v^{2}\right)} \\
\text { ここで, } \left.\begin{array}{l}
N=\left\{2 r_{0}^{3} \mp\left(2 r_{0}^{2}+R_{0}^{2}\right) \sqrt{r_{0}^{2}-R_{0}^{2}}\right\} / 3 \\
U=4 \sigma(1+W / 8) / \rho r_{0} \\
W=2 \rho r_{0} v^{2} / \sigma
\end{array}\right\}
\end{gathered}
$$

(28) 式の $N$ の式に含まれる正負の符号は (26) 式の条件に したがう.（27)式の $d^{*}$ に基ゔき，(25)式からRが求ま る.

\section{$2 \cdot 3$ 衝突速度 $v$}

(14)式のFを使用して, 滴の運動方程式が(29)式で与 えられる.

$$
-V d v / d t=\pi R_{0}^{2} v / 2
$$

$V$ は $\mathrm{ABCC}^{\prime} \mathrm{B}^{\prime} \mathrm{A}$ 部の体積であり, 幾何学的に(30)式に よつてvに関係づけることができる.

$$
V=(\pi / 3)\left(r_{0}+\int_{0}^{t} v d t\right)\left(2 r_{0}-\int_{0}^{t} v d t\right)^{2}
$$

$R_{0}$ は(24)式で与えられているので, (29) 式は非線形微 分積分方程式である. (31) 式の初期条件のもとで(29)式
の解は (32) 式となる（付録 B ).

$$
\begin{aligned}
& t=0 \text { で } v=v_{0} \\
& v=\frac{6 \sqrt{3}(2-\sqrt{3}) v_{0}\left\{1-(2-\sqrt{3}) \exp \left(-\sqrt{3} v_{0} t / 2 r_{0}\right)\right\}}{\left\{1+(2-\sqrt{3}) \exp \left(-\sqrt{3} v_{0} t / 2 r_{0}\right)\right\}^{3}} \\
& \cdot \exp \left(-\frac{\sqrt{3} v_{0} t}{2 r_{0}}\right)
\end{aligned}
$$

\section{4 薄膜流の完成時間 $\boldsymbol{t}_{c}$}

衝突過程が進行して, 滴の球形部の頂点 $\mathrm{A} か ゙$ 薄膜流の 厚さのレベルに達したとき, 滴は固体表面に沿つて, 十 分, のびきつた薄膜となる. この時点, $t=t_{c}$ では, $d^{*}$ が(33)式を満足すると考えられる.

$$
d^{*}=2 r_{0}-\int_{0}^{t_{c}} v d t
$$

(33)式を(23) および (B-7) 式（付録 B ）に適用すると, 表面張力を考虑しない場合の $t_{c}$ が $(34)$ 式で簡単に表わ せる。

$$
t_{c}=2.325 \quad r_{0} / v_{0}
$$

すなわち， $v_{0} t_{c}$ の值は滴径のみに依存する.

他方, 表面張力を考虑する場合の $t_{c}$ を簡単な解式の 形で示すことは困難である.すなわち，(33)式を式(27) に代入すると $\int_{0}^{t_{c}} v d t$ に関する 3 次方程式(35) となる.

$$
\begin{aligned}
& \left(32 \sigma+11 \rho r_{0} v^{2}\right) \phi_{c}^{3}-\left(176 \sigma r_{0}+64 \rho r_{0}^{2} v^{2}\right) \phi_{c}^{2}+ \\
& +\left(336 \sigma r_{0}^{2}+132 \rho r_{0}^{3} v^{2}\right) \phi_{c}-\left(192 \sigma r_{0}^{3}+96 \rho r_{0}^{4} v^{2}\right)=0
\end{aligned}
$$

ここで, $\phi_{c}=\int_{0}^{t_{c}} v d t$

(35) 式の実根 $\phi_{c}$ を(B-7) 式に代入して整理すると, $t_{c}$ が形式上(37)式で与えられる.

$$
t_{c}=-\left(2 r_{0} / 3 v_{0}\right) \cdot \ln \left[\frac{(2+\sqrt{3})\left\{1-\left(\phi_{c} / 3 r_{0}+1 / 3\right)^{\mathbf{1} / \mathbf{2}}\right.}{1+\left(\phi_{c} / 3 r_{0}+1 / 3\right)^{\mathbf{1} / 2}}\right]
$$

\section{3. 前章の理論と写真 ${ }^{1)}$ に基づく知見の比較}

WA:HTERS ら $220 \mathrm{~cm} / \mathrm{sec}$ の 3 種の条件で直径 $2 r_{0}=0.23 \mathrm{~cm}$ の水滴を $400^{\circ} \mathrm{C}$ に加熱した金の水平表面に鉛直方向から衝突させ て, 滴の変形過程を一連の側面写真に撮影した. 以下, 前章の理論から得られる結果を写真1)の計測から得た実 験的知見と比較する.

\section{$3 \cdot 1$ 衝突速度 $v$}

仮定 ( i ) に基づき，滴の頂点 $\mathrm{A}$ の移動速度 $v$ につて (32)式の理論曲線と実験結果を比較したのが Fig. 2 で ある、 $v_{0}$ が高い場合，および， $t$ が大きくなると理論か ら子想される衝突速度の減衰が実験結果にくらべて, 若 干はやくなる傾向が認められるが，両者は全体としてよ 


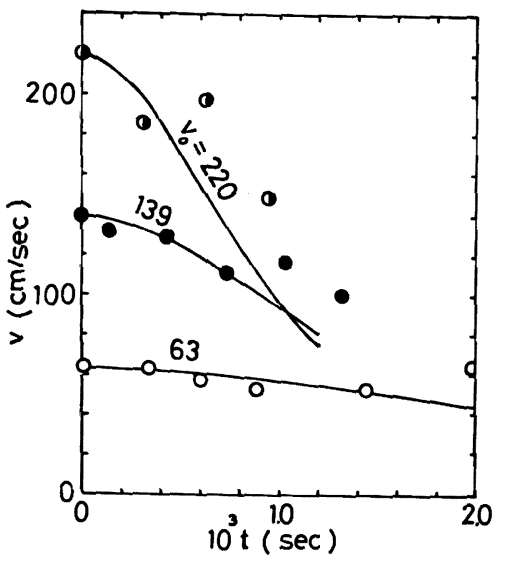

Fig. 2. Deceleration of the impinging droplet.

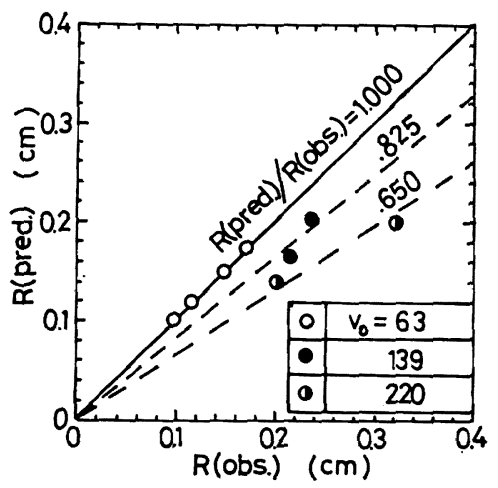

Fig. 3. Predicted radius, $R$ (pred.), from the observed circumference thickness and observed radius, $R$ (obs.), of the radially spreading thin film.

く一致しているといえる.

\section{$3 \cdot 2$ 整膜流の厚さ $d "$}

前述したように, 写真1)では, 滴底部薄膜流の周縁の プロフィルにさえぎられて, 薄膜の半径方向に沿つた厚 さ $d^{*}$ の実験值を直接知ることができない，そこで，か りに, 写真1に現われた薄膜周縁のプロフィルが $d^{*} を$ 表わすものとして，このものをvの実測值とともに(25) 式に代入してRの值を予測できる.もし，Rの予測値が， 写真1)に基づく $R$ の実測值に一致すれば，上述の $d^{*}$ に 関古る前提が正しいことになる. Fig. 3 でRの予測值と 实測值を比較した。この結果， $v_{0}=63$ では，両者がよく 一致しているが， $v_{0}=139$ および 220 の条件下で，予測 值が実測值にくらべて，それぞれ，82.5 および 65.0\% 程度の低い值となつた。したがつて，初期衝突速度が比 較的小さい条件では, 薄膜流の厚さ $d^{*}$ が薄膜の全面に わたつて，ほぼ，周縁の厚さにひとしいものと考えら
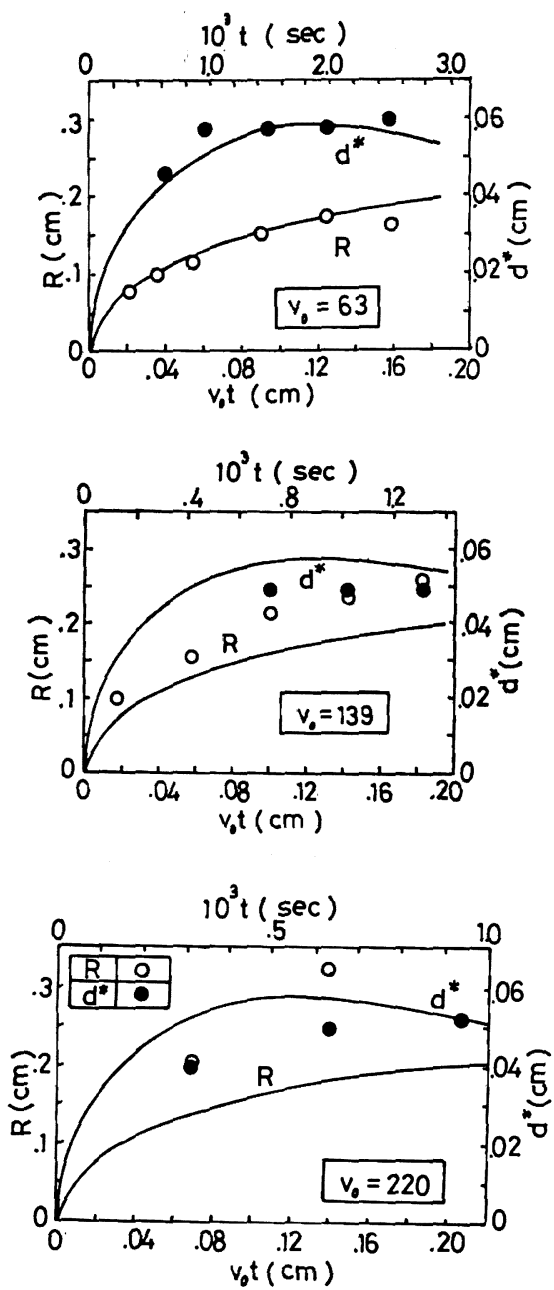

(a) $v_{0}=63 \mathrm{~cm} / \mathrm{sec}$ (b ) $v_{0}=139 \mathrm{~cm} / \mathrm{sec} \quad$ (c ) $v_{0}=220 \mathrm{~cm} / \mathrm{sec}$

Fig. 4. Theoretical curves by means of Eqs. (23) $\sim(26)$ and experimental data on $R$ and $d^{*}$.

れ, 一方, 初期衝突速度が大きくなるとともに, 周縁部 の厚さにくらべて膜流内部の厚さが小さくなつているも のと考えられる.

\section{$3 \cdot 3$ 薄膜流の半径 $\boldsymbol{R}$}

表面張力を考虑しない場合の関係(23)〜 (26)式に基ゔ くRの計算值と写真 ${ }^{1)}$ に基づく実測値とを比較したのが Fig. 4( a ) （c)である. 図では $d^{*}$ の計算值と前節に 述べた意味での実測值をあわせて比較した. $R$ および ${ }^{*}$ の理論曲線と実測值は， $v_{0}=63$ の場合によく一致した。 したがつて, 初期衝突速度が比較的小さい（We 数が比 較的小さい）条件下では, 表面張力効果を無視した簡単 な理論式(23)〜 (26)が十分なりたつことがわかる.

$v_{0}=139$ および 220 の場合の $R$ の理論曲線は実測値 


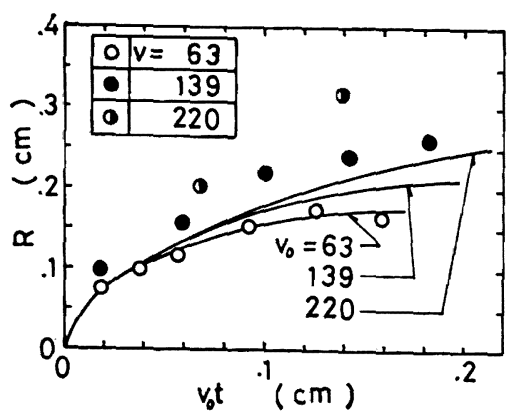

Fig. 5. Theoretical curves by means of Eqsg. (25) (28) and experimental data on $R$.

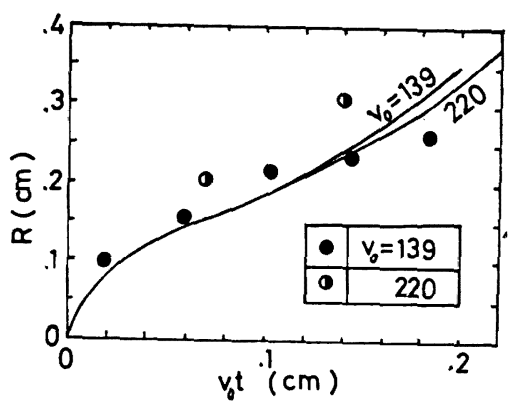

Fig. 6. Theoretical curves by means of Eqs. (39) and experimental data on $R$.

より小さくなるが，両者の数値のオーダーは一致してい る.

つぎに，表面張力を考虑した(25)〜 (28) 式に基ゔく $R$ の理論曲線を Fig. 5 に示す. 全体に理諭と実験の一致 関係が改善される傾向が認められる。

写真 ${ }^{1)}$ 心よれば， $v=220$ の条件では，薄膜流の周䋑 表面に凹凸部の存在を示す，表面の不均一性が悡められ る.このような表面の乱れは，周縁部の表面張力にたい して，薄膜流の慣性力が相対的に増大した結果であり， We 数の増大とともに顕著になる傾向と思われる. 薄膜 流の慣性力が薄膜周縁の表面張力上り十分大きい条件で は，(21）式右辺の第， 項を第 2 項にくらべて無視でき る.そこで，(21)式のかわりに(38)式がなりたつ.
$2 \sigma / r_{0}+\rho v^{2} / 2=\rho v_{R}^{2} / 2$

(38)式を(22)式に代入して整理すれば，(27)式にかわる 関倸として $R$ の (39)式を導くことができる.

$$
R=N V \bar{U} / 3 R_{0}^{2} v+V \overline{U\left(\bar{N} / R_{0}^{2} v\right)^{2}+R_{0}^{2}}
$$

ここで $N$ および $U$ は (28) 式で定燨したものと同一であ ๖.

(39)式に基づくRの計算值を Fig. 6 において㝝䮖值 と比較したＦig. 6 における理論上実験の一致は，Fig. 5 の場合にくらべて，さらに改善されている. $v_{0}=220$ の場合の理論值と実測值の偏差は $25 \%$ ていどである.

Fig. 6 では, $v_{0}=220$ の場合の理論曲線が $v_{0}=139$ の 場合のそれより下方に位置している。これは図の横軸と

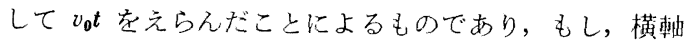
上して $t$ をえらぶなら， $v_{0}=220$ の場合の $R$ の理論曲線 は $v_{0}=139$ の場合のそれの上方にえがかれる.

\section{4 薄膜流の完成時間 $\boldsymbol{t}_{c}$}

(34)および(35)〜(37)式から求好た $t_{c}$ の值と写真1) に基づく $t_{c}$ を比較したのが Table 1 である、表面棖 力老考虑しない(34)式による計算值より，表面張力を考 虑した(35)〜(37) 式に基づく計筫值が，一層，実測值に 近い.

\section{4. 考察}

2 章の理論は薄膜流の擬定常解析に基幑をおいてい る. 実際の非定常的な衝突変形過程とこの理論の間のず れの大きさは， $R_{0}$ の㭙間的変化が $v$ にらべて無視て きるか否かに依存するので，衝突初期および末期に理論 曲線と実測值の差がもつとも大きくなると思われる.

Fig. 2 でvの理論曲線が末期に実測值からずれる傾向は このためであろう. Fig. 5 で $v_{0}=139$ および 220 の場 合の $R$ の理論曲線が実験結果からずれる理由も，上述の $v$ の理諭減衰が過大となる結果であり，実際には理論か ら予想される以上に慣性力が表面張力にくらべて大きい 值をもつのであろう、このような推論は，Fig. 6 で薄膜 流周縁の表面張力を無視した(39)式のRが $v_{0}=139$ の場 合に，ほぼ，実測值と一致したことから裏付けられる.

しかし，Fig. 6 で $v_{0}=220$ の条件下の理論曲線が実

Table 1. Calculated and observed values of $t_{r}$ for completion of the radially flowing thin film.

\begin{tabular}{c|c|c|c|}
\hline $\begin{array}{c}\text { Initial velocity of } \\
\text { impaction } \\
v_{0}(\mathrm{~cm})\end{array}$ & $\begin{array}{c}\text { Theoretical predictions } \\
10^{3} \mathrm{t}(\mathrm{s})\end{array}$ & $\begin{array}{c}\text { Experimental values }{ }^{1)} \\
10^{3} \mathrm{t}(\mathrm{s})\end{array}$ \\
\hline 63 & from Eq. (34) & frpm Eg. $(35) \sim(37)$ & 2.95 \\
139 & 4.24 & 1.73 & 3.06 \\
220 & 1.92 & 1.27 & 1.61 \\
1.22 & & 1.00 \\
\end{tabular}


值験からかなり（25\%ていど）低くなる点は，さらに別 の因子の存在与る可能性を示唆している，たとえば，そ れらの一つとして, 滴の球形残部の变形の問題および薄 膜流表面の不安定性が考えられる. これらの別の因子の 寄与の問題は実験的知見の蓄積とあわせて今後の課題で ある.いずれにせよ，本報で示した理論は基本的に実測 結果に適合し，かなりよく現象を説明するということが できる。

\section{5. 結言}

高温金属表面に衝突する水滴の变形過程について考察 した. 衝突運動に起因して生ずる滴底の薄膜流をポテン シャル流と考え, 流れの流速および压力分布の解を導い た. 滴の衝突速度は滴底および滴上表面の压力差によつ て減衰する。

薄膜流に関する物質収支と流れのエネルギー関係から 薄膜流の厚さと半径に関する理論式を誘導しWACHTERS ら1の写真から得た実験的知見と比較した。

初期衝突速度 $v_{0}=63 \mathrm{~cm} / \mathrm{sec}$ の場合は, 滴の表面張力 を考虑する場合，および，それを考虑しない場合の両方 の場合について, 薄膜流の厚さと半径に関する理論が実 測値によく一致する. $v_{0}=139 \mathrm{~cm} / \mathrm{sec} の$ 場合は，滴の球 形残部の表面張力を考虑して，薄膜流周縁部の表面張力 を無視して導いた薄膜流の半径に関する理論が実測結果 に適合したおおなじ理論に基づく $v_{0}=220 \mathrm{~cm} / \mathrm{sec}$ の場 合の薄膜流の半径の理論計算値は $25 \%$ ていどの偏差で 実測値と一致する.

本報で提出した理論は，スプレー冷却操作の伝熱過程 に関連して, 各衝突滴の伝熱面積の評価に有用な知見と 手法を提供する.

本研究は交部省科学研究費補助金 155270 に基うく研 究の一環であることを付言する.

付録A.（9) (12) 式の㹎出

(7)および(8)式を(1)および（2)式に代入すれば， 流れ関数 $\varphi$ について $(\mathrm{A}-1)$ 式を得る.

$$
\begin{gathered}
\frac{\partial \varphi}{\partial r} \cdot \frac{\partial}{\partial z}\left(E^{2} \varphi\right)-\frac{\partial \varphi}{\partial z}\left(E^{2}-\frac{3}{r^{2}}\right) \\
\left(\frac{\partial \varphi}{\partial r}-\frac{2}{r} \varphi\right)=0 \ldots \ldots \ldots \ldots \ldots \ldots \ldots \ldots \ldots \ldots \ldots \ldots \ldots \ldots . . .
\end{gathered}
$$

ただし， $\quad E^{2}=\partial^{2} / \partial r^{2}-(1 / r) \partial / \partial r+\partial^{2} / \partial z^{2} \ldots \cdots(\mathrm{A}-2)$

変数分離解に基うくく( $\mathrm{A}-1)$ 式の一般解は $(\mathrm{A}-3)$ 式とな る.

$$
\varphi=c_{1}+c_{2} z+c_{3} r^{2} z+c_{4} r^{2} z^{2}
$$

(A-3)式を（7）および（8）式に代入して，境界条件 (1)〜 (6) 式を適用すれば，解 (9)〜(11) 式を導くこと ができる。解(12)式は(9)および (10) 式を（1）および (2) 式に適用することによつて与えられる.
付録 B．（32) 式の粸出

衝突滴の $\mathrm{ABCC}^{\prime} \mathrm{B}^{\prime} \mathrm{A}$ 部 (Fig. 1) の消失速度は (B1)式で与えられる。

$$
-d V / d t=\pi R_{0}^{2} v
$$

(B-1)および (29)式から

$$
(1 / V) d V / d t=(2 / v) d v / d t
$$

(31) 式の条件, および, $t=0$ で $V=4 \pi r_{v}^{3} / 3$ の条件から $(\mathrm{B}-2)$ 式の解は ( B - 3) 式となる.

$$
V=\left(4 \pi r_{0}^{3} / 3\right)\left(v / v_{0}\right)^{2}
$$

(30)式を（B-3) 式に代入すれば（B-4) 式となる.

$$
\left(2 r_{0}-\int_{0}^{t} v d t\right)^{2}\left(r_{0}+\int_{0}^{t} v d t\right)=4 r_{0}^{3}\left(v / v_{0}\right)^{2}
$$

いま,

$$
\phi=\int_{0}^{t} v d t
$$

とおくと, (B-4)式は微分方程式 (B-6)に变換できる.

$$
\frac{d \phi}{d t}=\frac{v_{0}}{2 r_{0} \sqrt{r_{0}}}\left(2 r_{0}-\phi\right) \sqrt{r_{0}+\phi}
$$

(B-6) 式は容易に解くことができて, 解 (B-7)式が求ま る.

$$
\int_{0}^{t} v d t=3 r_{0}\left\{\frac{1-(2-V \overline{3}) \exp \left(-\sqrt{3} v_{0} t / 2 r_{0}\right)}{1+(2-\sqrt{3}) \exp \left(-\sqrt{3} v_{0} t / 2 r_{0}\right)}\right\}^{2}-r_{0}
$$

(B-7) 式を微分すれば(32) 式となる。

\section{記 号}

$d^{*}:$ 薄膜流の厚さ, $\mathrm{cm}$

$F:$ 過熱蒸気膜が衝突滴に及ぼす力, $\mathrm{g} / \mathrm{cm} \cdot \mathrm{sec}^{2}$

$P$ : 圧力 (大気圧基準), $\mathrm{g} / \mathrm{cm} \cdot \mathrm{sec}^{2}$

$P_{t}:$ 薄膜流の全圧, $\mathrm{g} / \mathrm{cm} \cdot \mathrm{sec}^{2}$

$R:$ 薄膜流の半径, $\mathrm{cm}$

$R_{0}$ : 衝突滴の球形部底面の半径, $\mathrm{cm}$

$r:$ 半径方向座標, $\mathrm{cm}$

$r_{0}$ : 滴の初期半径, $\mathrm{cm}$

$t:$ 時間, $\sec$

$t_{c}:$ 薄膜流の完成時間, $\mathrm{sec}$

$V$ : 衝突滴の球形部体積, $\mathrm{cm}^{3}$

$v$ : 衝突速度 (絶対值), $\mathrm{cm} / \mathrm{sec}$

$v_{0}$ : 初期衝突速度 (絶対值), $\mathrm{cm} / \mathrm{sec}$

$v_{R}: r=R$ での半径方向速度成分, $\mathrm{cm} / \mathrm{sec}$

$v_{R_{9}}: r=R_{0}$ での半径方向速度成分, $\mathrm{cm} / \mathrm{sec}$

$v_{r}:$ 半径方向流速成分, $\mathrm{cm} / \mathrm{sec}$

$v_{z}$ : 軸方向流速成分, $\mathrm{cm} / \mathrm{sec}$

$z$ : 軸方向位置座標, $\mathrm{cm}$

$\pi$ : 円周率, 一

$\rho:$ 液密度, $\mathrm{g} / \mathrm{cm}^{3}$

$\sigma$ : 表面張力, $\mathrm{g} / \mathrm{sec}^{2}$

$\varphi$ : 流れ関数, $\mathrm{cm}^{3} / \mathrm{sec}$

\section{交献}

l) $L . H$. Wachters and $N . A . J$. Westerling: Chem. Eng. Sci., 21 (1966), p. 1047

2 ) 森山 昭: 鉄と鋼, 59 (1973), p. 1245; Trans. ISIJ, 14 (1974), p. 285

3 ）森山 昭：鉄と鋼，59 (1973), p. 1373; Trans. ISIJ, 14 (1974), p. 290 